\title{
openheart Underuse of an invasive strategy for patients with diabetes with acute coronary syndrome: a nationwide study
}

\author{
Ida Gustafsson, ${ }^{1}$ Anders Hvelplund, ${ }^{2,3,4}$ Kim Wadt Hansen, ${ }^{2}$ Søren Galatius, ${ }^{2}$ \\ Mette Madsen, ${ }^{5}$ Jan Skov Jensen, ${ }^{2,6}$ Hans-Henrik Tilsted, ${ }^{7}$ \\ Christian Juhl Terkelsen, ${ }^{8}$ Lisette Okkels Jensen, ${ }^{9}$ Erik Jørgensen, ${ }^{7}$ \\ Jan Kyst Madsen, ${ }^{2,4}$ Steen Zabell Abildstrøm ${ }^{3,4,10}$
}

To cite: Gustafsson I, Hvelplund A, Hansen KW, et al. Underuse of an invasive strategy for patients with diabetes with acute coronary syndrome: a nationwide study. Open Heart 2015;2: e000165. doi:10.1136/ openhrt-2014-000165

Received 25 June 2014 Revised 5 September 2014 Accepted 19 November 2014

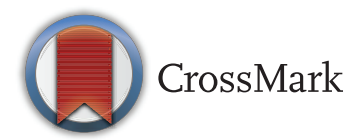

For numbered affiliations see end of article.

Correspondence to Dr Ida Gustafsson; gustafsson@dadlnet.dk

\section{ABSTRACT}

Background: Guidelines recommend an early invasive strategy for patients with diabetes with acute coronary syndromes (ACS). We investigated if patients with diabetes with ACS are offered coronary angiography (CAG) and revascularisation to the same extent as patients without diabetes.

Methods and results: The study is a nationwide cohort study linking Danish national registries containing information on healthcare. The study population comprises all patients hospitalised with first-time ACS in Denmark during 2005-2007 $(\mathrm{N}=24$ 952). Diabetes was defined as claiming of a prescription for insulin and/or oral hypoglycaemic agents within 6 months prior to the ACS event. Diabetes was present in $2813(11 \%)$ patients. Compared with patients without diabetes, patients with diabetes were older (mean 69 vs 67 years, $p<0.0001$ ), less often males ( $60 \%$ vs $64 \%, p=0.0001$ ) and had more comorbidity. Fewer patients with diabetes underwent CAG: cumulative incidence $64 \%$ vs $74 \%$ for patients without diabetes, $\mathrm{HR}=0.72(95 \% \mathrm{Cl} 0.69$ to $0.76, p<0.0001$ ); adjusted for age, sex, previous revascularisation and comorbidity $\mathrm{HR}=0.78(95 \% \mathrm{Cl}$ 0.74 to $0.82, p<0.0001)$. More patients with diabetes had CAG showing two-vessel or three-vessel disease $(53 \%$ vs $38 \%, p<0.0001)$. However, revascularisation after CAG revealing multivessel disease was less likely in patients with diabetes (multivariable adjusted $\mathrm{HR}=0.76,95 \% \mathrm{Cl} 0.68$ to $0.85, \mathrm{p}<0.0001$ ).

Conclusions: In this nationwide cohort of patients with incident ACS, patients with diabetes were found to be less aggressively managed by an invasive treatment strategy. The factors underlying the decision to defer an invasive strategy in patients with diabetes are unclear and merit further investigation.

\section{INTRODUCTION}

An increasing proportion of patients hospitalised with acute coronary syndromes (ACS) have concomitant diabetes. This patient group has an adverse prognosis, including a higher long-term mortality rate, which is not

\section{KEY MESSAGES}

What is already known about this subject?

- Patients presenting with acute coronary syndromes (ACS) and concomitant diabetes mellitus (DM) constitute a high-risk group and have a more adverse prognosis than patients without DM. Despite randomised clinical trials showing a benefit of an early invasive strategy in patients with diabetes presenting with ACS of at least the same magnitude as in patients without DM, prior reports suggest an underuse of evidencebased medication and cardiac catheterisation in this subset of patients.

What does this study add?

- In this nationwide study of patients with incident ACS in a modern invasive treatment setting, we found that patients with DM remained a highrisk group, but were significantly less likely to undergo coronary angiography and subsequent revascularisation than patients without DM, even after adjusting for conventional risk factors. Noticeably, in the subgroup of patients with an available angiogram showing multivessel disease, patients with DM were not as aggressively revascularised as patients without DM.

How might this impact on clinical practice?

- Our findings suggest that physicians need to be aware of a potential treatment-risk paradox with an underuse of invasive treatment strategies in patients with DM hospitalised with ACS. However, future studies are needed to further clarify the reasons why physicians refrain from using cardiac catheterisations in patients with DM.

fully explained by a clustering of risk factors and more comorbidity in patients with diabetes. $^{1-4}$ Several studies have proven the benefit of an invasive strategy in patients with diabetes of at least the same magnitude as in patients without diabetes in the setting of ST-elevation myocardial infarction $(\text { STEMI })^{5-7}$ as well as non-ST-elevation 
ACS. ${ }^{8} 9$ Thus, current and previous guidelines recommend an early invasive strategy for patients with diabetes with ACS. ${ }^{10-13}$ In Denmark, guidelines have recommended an immediate invasive strategy for all patients with STEMI following the results of the DANAMI 2 trial, ${ }^{6}$ and an early invasive strategy for patients without STEMI following the publication of the FRISC 2 trial. ${ }^{14}$ Importantly, observational studies have found that adherence to guidelines improves outcome. ${ }^{15} 16$

Nonetheless, several previous reports have elucidated underuse of evidence-based medication and cardiac catheterisation in patients with ACS with diabetes. ${ }^{3}{ }^{17-19}$ Some of these reports contain data that are not contemporary and therefore with a low overall rate of invasive examination. ${ }^{3} 1718$ In one study, the lower frequency of cardiac catheterisation was confined to insulindependent patients with diabetes and based on in-hospital data only. ${ }^{19}$ Other studies have found no disparities in cardiac catheterisation rates in patients with and without diabetes. ${ }^{20-22}$

The present study was performed in order to evaluate if patients with diabetes with ACS are offered coronary angiography (CAG) and revascularisation to the same extent as patients without diabetes in a contemporary real-world setting. For this purpose we used nationwide registries to investigate all admissions for ACS in Denmark (5.4 million inhabitants) in 2005-2007.

\section{METHODS}

\section{Study population}

The study was designed as a retrospective observational nationwide cohort study linking Danish national registers containing information on vital status, hospitalisations, revascularisation procedures, coronary pathology revealed by CAG and claiming of drug prescriptions. The method and study population have been described in detail previously. ${ }^{23}$

Information on admissions and comorbidity was obtained from the Danish National Patient Registry, which holds information on all admissions to all Danish hospitals since 1978. Each hospitalisation is registered by one primary final discharge diagnosis and, if appropriate, one or more secondary diagnoses according to the International Classification of Diseases (ICD) - the 8th revision (ICD-8) before 1994 and the 10th revision (ICD-10) after 1994.

All patients, 30-90 years of age, admitted with acute myocardial infarction (MI), including STEMI and non-STEMI (NSTEMI), or unstable angina pectoris (UAP) as the primary discharge diagnosis (ICD-10 codes: I20.0, I21) in the period January 2005 through December 2007, were identified. To study first admissions with ACS, we excluded patients with a previous diagnosis of MI 1978-1993 (using ICD-8 code 410), or ACS since 1994. The definitions of MI and UAP in Denmark follow the guidelines from the European Society of Cardiology. Patients discharged on the day of admission were excluded to ensure that the ACS diagnosis was based on reliable observations including sampling of biochemical markers. Likewise, patients not surviving the day of admission were excluded in order to avoid the potential bias that these patients would not be eligible for cardiac catheterisation due to early death shortly after their admission. The MI diagnosis in the registry has been validated by comparison with the results from the MONICA database, revealing a high sensitivity and specificity of $90-95 \% .^{24}$

\section{Exposure variable}

Diabetes was defined as claiming of a prescription for insulin and/or oral hypoglycaemic agents (OHA) within 6 months prior to the ACS event. Thus, patients diagnosed with diabetes mellitus during the index admission for ACS were not included in the diabetes group. Information on drug prescription was obtained from The Danish Register of Medicinal Product Statistics, which includes information about all prescriptions dispensed from pharmacies in Denmark since 1995. As all residents in Denmark are covered by a national health insurance system and get the cost of drugs partly reimbursed, all pharmacies are required by law to register on an individual level all prescriptions dispensed.

\section{Explanatory variables}

Information on the extent of coronary artery disease among patients examined by CAG was obtained from the Danish Heart Registry (http://si-folkesundhed.dk/ Links/Dansk\%20Hjerteregister.aspx), which includes all invasive examinations and procedures performed at Danish hospitals since year 2000. A significant lesion was defined as at least $50 \%$ diameter stenosis in a major epicardial vessel or coronary artery bypass graft (CABG).

Primary and secondary diagnoses at the index admission and at admissions up to 1 year before the index admission were used to define comorbidity. Diagnoses of congestive heart failure, cardiogenic shock, arrhythmia and pulmonary oedema were considered, reflecting the severity of the heart disease, while diagnoses of malignancy, cerebrovascular disease, acute renal failure and chronic renal failure indicated comorbidity. This method is an extension of the Ontario MI mortality prediction rule ${ }^{25}$ with translation to ICD-10 codes validated by So $e t a l .^{26}$ The age of each patient was categorised into 10 year intervals and was used as a categorical variable.

Previous revascularisation within 5 years of index event was recorded for each patient, as this might affect the decision to perform an invasive examination.

\section{Outcome}

Information on the patient's vital status was obtained from The Danish Civil Registration System. We estimated the effect of diabetes on the chance of CAG and on subsequent revascularisation (percutaneous coronary intervention (PCI) or CABG) for those having had a CAG 
performed within 60 days of admission. A 60-day observation period was used to include as many examinations and procedures as possible and, at the same time, to avoid angiography performed because of reinfarctions. Since differences in mortality could potentially influence the rates of procedures, we used a competing risks model to analyse the data. ${ }^{27}$ Cumulative incidence curves were calculated for the incidence of CAG in the whole study population and of revascularisation in the CAG population, and the cumulative incidence at 60 days was read from the curves.

Differences in clinical presentation of disease could affect the timing of the invasive CAG. We therefore performed a stratified analysis of CAG procedures, dividing them into acute or early invasive examination, being on the day of admission or the day after, and subacute from day 2 until day 60.

\section{Statistical methods}

Discrete data are presented as frequencies and percentages. Continuous variables are presented as mean with SD for characteristics with appropriately near-symmetrical distributions or as median (IQR). Differences in baseline characteristics between patients with and without diabetes were evaluated using a $\chi^{2}$ test for categorical variables and the non-parametric Mann-Whitney $U$ test for continuous variables.

Cumulative incidence curves were estimated in a competing risks model with the SAS-macro developed by Rosthoj et al. ${ }^{28}$ Differences in outcome were estimated using Cox proportional hazards model. Outcome variables were CAG in the entire population and revascularisation (PCI or CABG) in patients in whom CAG was performed. In the multivariable analysis, covariates considered to have potential impact on the decision to perform CAG and subsequent revascularisation were entered in three steps. First, the basic confounder's age and sex were entered. Second, year of admission prior PCI or CABG, and comorbidity were added to the model. Lastly, socioeconomic variables were added. Model assumptions-linearity, proportional hazards and interactions-were tested and found valid unless otherwise indicated. All hypotheses tested had a 0.05 significance level. All tests were two-sided. Since an interaction between diabetic status and number of diseased vessels found by CAG with regard to chance of revascularisation was found, separate Cox analyses were performed for one-vessel, two-vessel and three-vessel disease.

As a sensitivity analysis, we used propensity score analysis to identify a set of cases (patients with diabetes) and controls (patients without diabetes), who were matched with respect to age, comorbidity, admission year, admission diagnosis and previous revascularisation. A propensity score was quantified by multivariable logistic regression. Concordance statistic (C statistic) of the model was 0.77 , indicating good discriminative capabilities between the two exposure groups. ${ }^{29}$ A Greedy matching macro (by Lori S Parsons, accessed 14 April
2009, at http://www2.sas.com/proceedings/sugi26/ p214-26.pdf) was used to match each case to one control. A multivariable-adjusted Cox-model was fitted, including the propensity score. All analyses were performed with SAS statistical software package V.9.13 (SAS Institute, Inc, Cary, North Carolina, USA).

\section{RESULTS}

\section{Demographic data}

During the 3-year study period 24952 patients were hospitalised with first-time ACS and survived the first day. Diabetes was present in $2813(11 \%)$ patients. Among these, $60 \%$ were treated with OHA, $12 \%$ with insulin, and $28 \%$ with a combination of insulin and OHA. Baseline characteristics for patients with and without diabetes are presented in table 1 . Compared with patients without diabetes, patients with diabetes were older (mean 69 vs 67 years, $\mathrm{p}<0.0001$ ), less often male ( $60 \%$ vs $64 \%, \mathrm{p}=0.0001$ ) and had more comorbidity, in particular, cardiovascular and renal diseases, but not malignant diseases. In accordance with the higher frequency of comorbidities, patients with diabetes were prescribed more medications prior to the ACS hospitalisation. Patients with diabetes had lower socioeconomic status, but lived as close to the invasive centres as patients without diabetes. Few patients had been revascularised within the preceding 5 years $(5.3 \%$ in the diabetic group and $3.3 \%$ in the non-diabetic group, $\mathrm{p}<0.001)$. The final diagnosis was acute $\mathrm{MI}$ in $83 \%$ and unstable angina in $17 \%$, with no difference between patients with and without diabetes. Information about race was not available, but the vast majority of patients in Denmark are Caucasian. During the 60-day follow-up, 380 (13\%) patients with diabetes and 2008 (9\%) patients without diabetes died (figure 1, table 2).

\section{Coronary angiography}

Fewer patients with diabetes underwent CAG: cumulative incidence $64 \%$ vs $74 \%$ for patients without diabetes (figure 2), $\mathrm{HR}=0.72,95 \%$ CI 0.69 to $0.76, \mathrm{p}<0.0001$. Adjustment for age, sex, previous revascularisation, comorbidity and socioeconomic variables did not change the estimate substantially: $\mathrm{HR}=0.79$ (95\% CI 0.76 to 0.83 , $\mathrm{p}<0.0001$; table 3 ). In the propensity score matched analysis, 2626 patients with diabetes were matched one-to-one with 2626 patients without diabetes. The propensity adjusted Cox model yielded a $\mathrm{HR}$ of 0.88 (95\% CI 0.82 to $0.94, p=0.0001)$. The lower CAG rate was especially pronounced for acute invasive investigation performed on the day of admission or the day after (25\% vs $37 \%, \mathrm{p}<0.0001$; table 2). Multivariable adjustment for the possible confounders mentioned above confirmed this result: HR for CAG on the day of admission or the day after ACS was 0.69 (0.64 to $-0.75, \mathrm{p}<0.0001)$, while HR for CAG on day 2-60 after ACS was 0.88 (0.82 to 0.94, $\mathrm{p}<0.0001)$ comparing patients with and without diabetes. 
Table 1 Baseline characteristics of patients with and without diabetes

\begin{tabular}{|c|c|c|c|}
\hline & $\begin{array}{l}\text { Diabetes } \\
\mathrm{N}=2813 \text { (11) }\end{array}$ & $\begin{array}{l}\text { No diabetes } \\
\mathrm{N}=22139(89)\end{array}$ & p Value \\
\hline Male gender & $1692(60)$ & $14128(64)$ & 0.0001 \\
\hline Age in years, mean (SD) & $69.2(11.8)$ & $67.0(13.1)$ & $<0.0001$ \\
\hline Hospital stay in days, median (Q1-Q3) & $7(4-12)$ & $6(4-10)$ & $<0.0001$ \\
\hline Distance to invasive centre & & & 0.19 \\
\hline Close $(<21 \mathrm{~km})$ & $946(34)$ & $7275(33)$ & \\
\hline Intermediate distance (21-64 km) & $880(31)$ & 7340 (33) & \\
\hline Long distance (>64 km) & $984(35)$ & $7485(34)$ & \\
\hline Unknown & $3(0.1)$ & $39(0.2)$ & \\
\hline Revascularisation within the past 5 years & $150(5)$ & $733(3)$ & $<0.0001$ \\
\hline \multicolumn{4}{|l|}{ Comorbidity } \\
\hline Congestive heart failure & $447(16)$ & $2061(9)$ & $<0.0001$ \\
\hline Pulmonary oedema & $42(2)$ & $157(1)$ & $<0.0001$ \\
\hline Shock & $23(1)$ & $123(1)$ & 0.09 \\
\hline Arrhythmia & $417(15)$ & $2492(11)$ & $<0.0001$ \\
\hline Cerebrovascular disease & $235(8)$ & $994(5)$ & $<0.0001$ \\
\hline Chronic obstructive pulmonary disease & $196(7)$ & $1288(6)$ & 0.02 \\
\hline Chronic renal failure & $109(4)$ & $297(1)$ & $<0.0001$ \\
\hline Acute renal failure & $50(2)$ & $176(1)$ & $<0.0001$ \\
\hline Malignancy & $71(3)$ & $583(3)$ & 0.73 \\
\hline Educational level & & & $<0.0001$ \\
\hline Elementary school & $1284(46)$ & $8239(37)$ & \\
\hline High school & $947(34)$ & $8750(40)$ & \\
\hline Bachelor or higher & $276(10)$ & $2973(13)$ & \\
\hline Unknown & $306(11)$ & $2177(10)$ & \\
\hline Income & & & $<0.0001$ \\
\hline Low & 1099 (39) & $7001(32)$ & \\
\hline Medium & $953(34)$ & 7211 (33) & \\
\hline High & $746(27)$ & $7823(35)$ & \\
\hline Unknown & $15(1)$ & $104(1)$ & \\
\hline Living alone & $1236(44)$ & $8103(37)$ & $<0.0001$ \\
\hline Discharge diagnosis & & & 0.14 \\
\hline Acute myocardial infarction & $2322(83)$ & $18515(84)$ & \\
\hline Unstable angina pectoris & $491(17)$ & $3624(16)$ & \\
\hline \multicolumn{4}{|l|}{ Medication before admission } \\
\hline Loop diuretics & $910(32)$ & 2671 (12) & $<0.0001$ \\
\hline Lipid lowering drugs & $1454(52)$ & 4129 (19) & $<0.0001$ \\
\hline$\beta$ blockers & $854(30)$ & $4661(21)$ & $<0.0001$ \\
\hline ACE-I/ARB & $1680(60)$ & $5273(24)$ & $<0.0001$ \\
\hline Aspirin & $1390(49)$ & $5964(27)$ & $<0.0001$ \\
\hline Clopidogrel & $121(4)$ & $487(2)$ & $<0.0001$ \\
\hline
\end{tabular}

Values are numbers with percentage in parenthesis unless otherwise indicated.

ACE-I/ARB, ACE inhibitors/angiotensin receptor blockers.

In figure 3, the results of CAG in the diabetic and non-diabetic groups are depicted. More patients with diabetes had CAG showing two-vessel or three-vessel disease $(53 \%$ vs $38 \%, \mathrm{p}<0.0001)$.

\section{Revascularisation}

Overall, the frequency of revascularisation (PCI or CABG) in patients with diabetes was substantially lower than in patients without diabetes ( $47 \%$ vs $57 \%$, p $<0.0001$; table 2$)$. This was partly explained by a lower CAG rate in patients with diabetes. Considering only patients who were invasively investigated by CAG, $73 \%$ of patients with diabetes and $77 \%$ of patients without diabetes were revascularised $(\mathrm{p}=0.0002)$. The frequency and method (PCI and/or CABG) of revascularisation differed according to diabetic status and number of diseased vessels (table 4). The difference in revascularisation rates between patients with and without diabetes increased with more severe coronary pathology. In one-vessel and two-vessel disease, the frequencies of PCI were lower in patients with diabetes. In three-vessel disease both rates of PCI and of CABG were lower. Multivariable analyses revealed no significant difference between patients with and without diabetes in chance of revascularisation if CAG had shown one-vessel disease (table 5). However, patients with diabetes with multivessel disease had a $24 \%$ less chance of being revascularised. 
Figure 1 Mortality during the first 60 days after first-time acute coronary syndrome in patients with and without diabetes.
Mortality curves (1 - kaplan meier estimator)

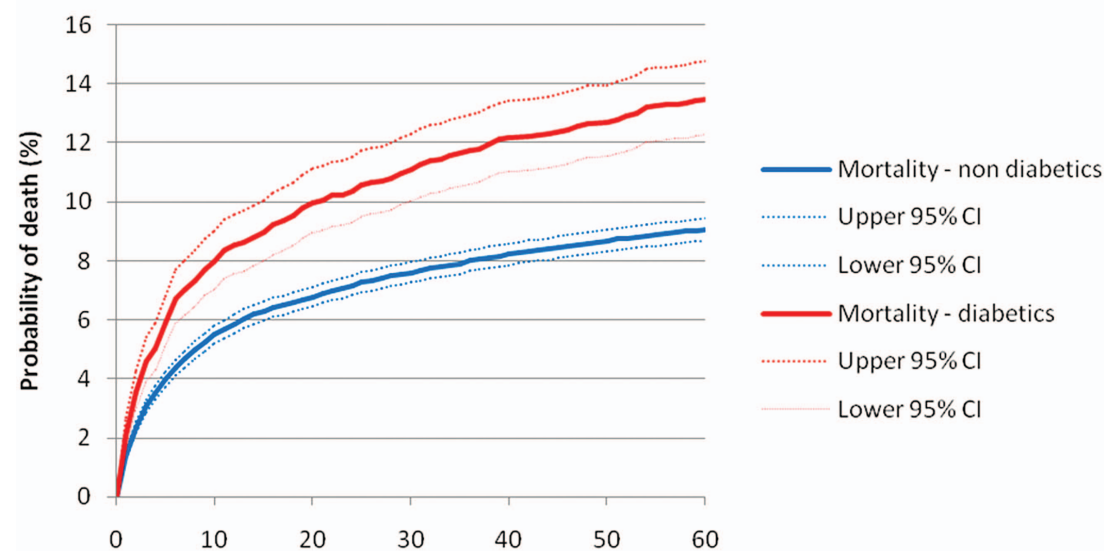

\section{DISCUSSION}

The main results of this study are that patients with ACS with diabetes in the modern invasive treatment era remain a high-risk group but, paradoxically, CAG is performed significantly less often in these patients. Furthermore, among the patients with ACS who underwent $\mathrm{CAG}$, the angiogram in patients with diabetes more often revealed multivessel disease, which was not revascularised as often as for patients without diabetes.

The prevalence of diabetes in the current cohort is somewhat lower than in most other studies, which is most likely explained by the fact that only patients with first-time ACS were included and that diet-treated patients with diabetes were not categorised as having diabetes. ${ }^{1} \quad 3 \quad 4 \quad 17-22$ Also, the prevalence of diabetes in Denmark is lower than in many other industrialised countries including, especially, North America. Total mortality at 60 days was $9.6 \%$ with an almost $50 \%$ higher mortality rate in patients with diabetes. The total mortality in the current study is rather high, which can be explained by the nature of the study population comprising unselected patients with an age up to 90 years. The excess mortality in patients with diabetes has a magnitude similar to that found in previous studies. ${ }^{1-4}$

\begin{tabular}{|c|c|c|c|}
\hline & $\begin{array}{l}\text { Diabetes } \\
\mathrm{N}=2813 \\
(11)\end{array}$ & $\begin{array}{l}\text { No } \\
\text { diabetes } \\
\mathrm{N}=22139 \\
(89)\end{array}$ & p Value \\
\hline Death within 60 days & $380(13)$ & $2008(9)$ & $<0.0001$ \\
\hline Acute $^{\star}$ CAG & $698(25)$ & $8170(37)$ & $<0.0001$ \\
\hline Acute $^{\star}$ revascularisation & $584(21)$ & $7123(32)$ & $<0.0001$ \\
\hline CAG within 60 days & $1796(64)$ & $16466(74)$ & $<0.0001$ \\
\hline $\begin{array}{l}\text { Revascularisation within } \\
60 \text { days }\end{array}$ & $1310(47)$ & $12655(57)$ & $<0.0001$ \\
\hline
\end{tabular}

Some conditions, such as cancer with short expected lifetime, very old age and severe renal disease, should in fact prevent an invasive investigation. Despite inclusion of these factors in the multivariable statistical analyses, the chance of CAG was found to be about $20 \%$ less for patients with diabetes. Since patients with diabetes had lower socioeconomic status, and a previous study has indicated that patients' income affects the chance of revascularisation-even in Denmark, where all patients are covered by a universal health insurance ${ }^{30}$ - socio- $^{-}$ economic variables were also accounted for in the statistical models without affecting the estimate. A putative explanation that could not be accounted for in the current study is that patients with diabetes to a higher degree did not accept an invasive strategy even though this examination was recommended by the physician. However, few patients decline recommended interventions, and it seems unlikely that this could explain the large difference in CAG rate. ${ }^{31}$ Furthermore, post-MI complications such as heart failure and renal dysfunction, which are more common in patients with diabetes and might prevent an invasive strategy, could not be accounted for. Conversely, a time period of 60 days after the ACS event was applied, that is, CAG procedures performed after discharge in stabilised patients were included in the analyses. A variety of barriers can prevent physicians from adhering to guidelines. Apart from external factors, the barriers might comprise lack of awareness, lack of agreement with guidelines and inertia of previous practice. ${ }^{32}$ The last mentioned factors should not be relevant to this matter, since large well conducted studies on the effect of an invasive strategy were published several years before the data collection for the current study. Lack of awareness regarding the use of risk scores in non-ST-segment elevation ACS, such as the GRACE risk score, which has been proven to be beneficial, might however be a relevant factor. ${ }^{33}$ Guidelines on risk stratification in ACS before 2005, when this study started, focused on ECG changes and biomarker level but not on the use of risk scores, although diabetes was mentioned as a risk factor. ${ }^{11}$ Also, insights from the CRUSADE 
Figure 2 Cumulative incidence curves illustrating the chance of coronary angiography in patients with and without diabetes when alive during the first 60 days after first-time acute coronary syndrome.
Cumulative incidence curves coronary angiography $\mathrm{n}=\mathbf{2 4} 952$

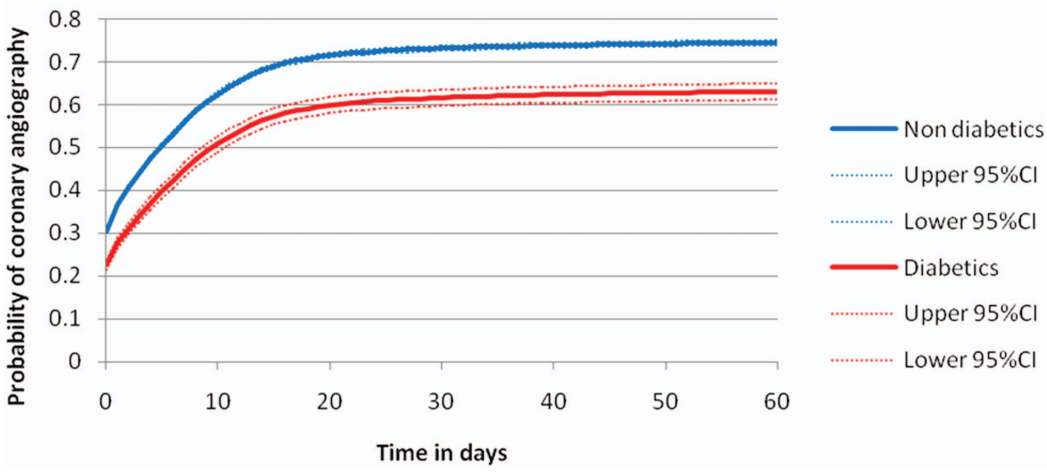

Quality Improvement Initiative in the $\mathrm{USA}^{34}$ and the Canadian ACS registries have revealed that physician risk stratification is suboptimal, resulting in a treatment-risk paradox implicating a lower chance of undergoing CAG in high-risk patients who more often have diabetes. ${ }^{35-37}$ Improving adherence to guidelines and quality of patient care encompass comprehensive approaches at different levels. The most effective approaches seem to be interactive educational meetings, the use of feedback systems, computerised decision support and combined interventions. ${ }^{38}$ Whether application of these methods will result in greater utilisation of an invasive strategy in patients with high-risk diabetic ACS remains to be determined.

The acute CAG rate was particularly low for patients with diabetes, which might partly be explained by differences in presentation between patients with and without diabetes. Some studies have shown that patients with ACS with diabetes present less often with STEMI, ${ }^{4} 18$ while others have not. ${ }^{20}$ Also, some studies have found patients with diabetes to present less often with chest pain $^{20}$ and to have a greater delay from symptom onset to hospital arrival. ${ }^{42}$ Unfortunately, the STEMI diagnosis in the Danish National Patient Registry has not been validated and cannot be used for the current study. However, if in the current study the proportion of STEMI among patients with diabetes had been lower, then the fraction of NSTEMI and UAP should have been higher resulting in a higher rate of non-acute CAG, which was not the case. Nevertheless, patients with
ACS with diabetes may benefit more from early invasive treatment than patients without diabetes emphasising the importance of a quick diagnosis and referral for CAG. $^{39}$

The finding of more severe coronary artery disease in patients with diabetes is in accordance with other studies. ${ }^{4} 2033$ To the best of our knowledge, no previous studies have published data regarding PCI and CABG rates according to findings of CAG in unselected patients with ACS with diabetes. Data from the Euro Heart survey have shown that angiography followed by intervention is less common in patients with diabetes in NSTEMI, but not in STEMI. ${ }^{4}$ In this report, no multivariable analyses were presented and data regarding procedures after discharge were incomplete. Our data imply that most patients with ACS due to one-vessel disease are revascularised without difference according to diabetic status. However, for three-vessel disease the revascularisation rate is lower, especially for patients with diabetes, although the prognostic impact of revascularisation has been well documented for this group. ${ }^{10}$ The decision to defer revascularisation ought not to be based on comorbidity in most cases, since a CAG should not be performed if subsequent revascularisation is not an option. Yet, there might be situations where patients are offered CAG with the intention to perform PCI if possible but not CABG. After controlling for comorbidity and other possible confounders, the statistical model showed a striking $24 \%$ less chance of revascularisation in

Table 3 Chance of coronary angiography within 60 days for patients with diabetes compared with patients without diabetes admitted with acute coronary syndromes $(\mathrm{N}=24$ 952)

\begin{tabular}{lcccr}
\hline & Model 1 & Model 2 & Model 3 & Model 4 \\
\hline $\mathrm{HR}$ & 0.72 & 0.74 & 0.78 & 0.79 \\
$95 \% \mathrm{Cl}$ & 0.69 to 0.76 & 0.70 to 0.78 & 0.74 to 0.82 & 0.76 to 0.83 \\
$\mathrm{p}$ Value & $<0.0001$ & $<0.0001$ & $<0.0001$ & $<0.0001$ \\
\hline
\end{tabular}

Model 1: Unadjusted.

Model 2: Adjusted for age group and sex.

Model 3: Adjusted for age group, sex, year of admission, previous revascularisation and comorbidity.

Model 4: Adjusted for age group, sex, year of admission, previous revascularisation, comorbidity and socioeconomic variables (educational level, income, living alone). 


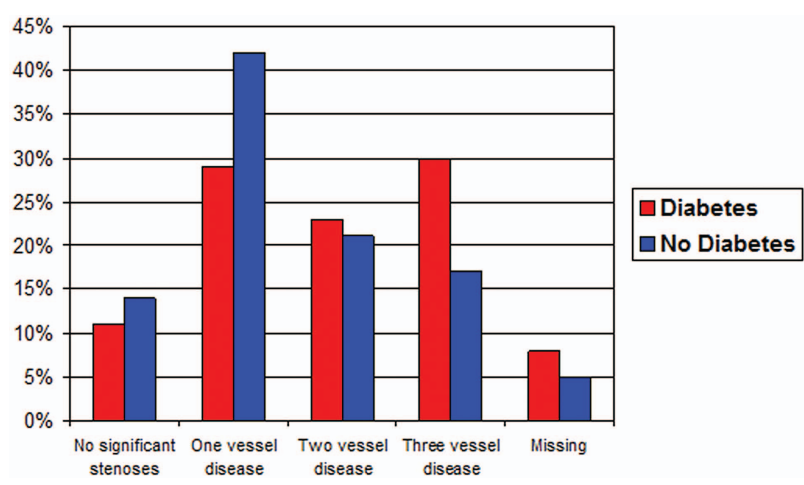

Figure 3 Result of coronary angiogram among patients with and without diabetes admitted with first-time acute coronary syndrome (a significant stenosis was defined as at least $50 \%$ diameter reduction in a major epicardial vessel or coronary artery bypass graft).

patients with diabetes with both two-vessel and threevessel disease. The most likely explanation is that revascularisation was not technically feasible due to a higher frequency of diffuse and peripheral coronary artery disease. ${ }^{40}$ Future studies investigating if this is the case are needed. Also, research into alternative treatment strategies for patients with diabetes with multivessel disease without options for revascularisation is urgently needed.

The strength of the present study is that the study cohort is nationwide and therefore unselected. Owing to the high quality of the national registries, many different characteristics of the patients including result of CAG are available.

The main limitation is that of the observational register-based design. Only comorbidities registered during hospitalisations were available, while milder forms, for example, peripheral artery disease and renal dysfunction managed out-of-hospital were not accounted
Table 5 Chance of revascularisation within 60 days for patients with diabetes compared with patients without diabetes admitted with acute coronary syndromes according to result of $\mathrm{CAG}$

\begin{tabular}{|c|c|c|c|}
\hline Result of CAG & HR & Cl & p Value \\
\hline $\begin{array}{l}\text { One-vessel disease } \\
(\mathrm{N}=7468)\end{array}$ & 0.92 & 0.83 to 1.01 & 0.07 \\
\hline $\begin{array}{l}\text { Two-vessel disease } \\
(\mathrm{N}=3922)\end{array}$ & 0.76 & 0.68 to 0.85 & $<0.0001$ \\
\hline $\begin{array}{l}\text { Three-vessel disease } \\
(\mathrm{N}=3413)\end{array}$ & 0.76 & 0.68 to 0.85 & $<0.0001$ \\
\hline
\end{tabular}

Multivariable model with age group, sex, year of admission, previous revascularization and comorbidity as covariates. CAG, coronary angiography.

for. Likewise, information on ECG changes, biomarkers and complications such as heart failure or renal failure after the ACS event, which could also influence the decision to apply an invasive strategy, was not available. Thus, unmeasured confounding cannot be ruled out.

Patients with diet-controlled diabetes, who were classified as patients without diabetes in the current study, are expected to have a better prognosis than patients with diabetes requiring antidiabetic medication. ${ }^{2}$ Therefore, patients with diet-controlled diabetes might have less advanced coronary artery disease and comorbidity preventing an invasive strategy. If, however, patients with diet-treated diabetes are similar to patients with diabetes requiring antidiabetic medication, then the presented results are likely to underestimate the real difference in CAG rate between patients with and without diabetes.

\section{CONCLUSION}

In this nationwide cohort of patients with first-time ACS, patients with diabetes were found to be less aggressively managed by an invasive strategy. The factors underlying

Table 4 Frequency of revascularisation (PCI and/or CABG) within 60 days after acute coronary syndromes for patients with and without diabetes according to number of diseased vessels revealed by coronary angiography

\begin{tabular}{|c|c|c|c|}
\hline & $\begin{array}{l}\text { One-vessel disease } \\
N(D M)=512 \\
N(\text { non-DM) }=6956\end{array}$ & $\begin{array}{l}\text { Two-vessel disease } \\
N(\text { DM) }=407 \\
N(\text { non-DM) }=3515\end{array}$ & $\begin{array}{l}\text { Three-vessel disease } \\
N(D M)=541 \\
N(\text { non-DM) }=2872\end{array}$ \\
\hline \multicolumn{4}{|l|}{$\mathrm{PCl}$} \\
\hline DM & $451(88)$ & $313(77)$ & $255(47)$ \\
\hline Non-DM & $6302(91)$ & $3030(86)$ & $1539(54)$ \\
\hline p Value & 0.06 & $<0.0001$ & 0.006 \\
\hline \multicolumn{4}{|l|}{ CABG } \\
\hline $\mathrm{DM}$ & $6(1)$ & 47 (12) & $173(32)$ \\
\hline Non-DM & $94(1)$ & $321(9)$ & $1037(36)$ \\
\hline p Value & 0.73 & 0.11 & 0.07 \\
\hline \multicolumn{4}{|c|}{$\mathrm{PCl}$ and/or $\mathrm{CABG}$} \\
\hline DM & 454 (89) & $352(87)$ & $404(75)$ \\
\hline Non-DM & $6360(91)$ & 3271 (93) & 2392 (83) \\
\hline p Value & 0.03 & $<0.0001$ & $<0.0001$ \\
\hline
\end{tabular}

Data are presented as numbers with percentages in parenthesis.

CABG, coronary artery bypass grafting; DM, diabetes mellitus; $\mathrm{PCl}$, percutaneous coronary intervention. 
the decision to defer an invasive strategy in patients with diabetes are unclear and merit further investigation.

\section{Author affiliations}

${ }^{1}$ Department of Cardiology, Hvidovre University Hospital, Hvidovre, Denmark ${ }^{2}$ Department of Cardiology, Gentofte University Hospital, Hellerup, Denmark ${ }^{3}$ National Institute of Public Health, University of Southern Denmark, Copenhagen, Denmark

${ }^{4}$ Danish Heart Registry, Copenhagen, Denmark

${ }^{5}$ Institute of Public Health, University of Copenhagen, Copenhagen, Denmark

${ }^{6}$ Faculty of Health Sciences, Institute of Surgery and Internal Medicine,

University of Copenhagen, Copenhagen, Denmark

${ }^{7}$ Department of Cardiology, Rigshospitalet, Copenhagen, Denmark

${ }^{8}$ Department of Cardiology, Aarhus University Hospital, Skejby, Denmark

${ }^{9}$ Department of Cardiology, Odense University Hospital, Odense, Denmark

${ }^{10}$ Department of Cardiology, Bispebjerg University Hospital, Copenhagen, Denmark

Contributors IG and AH obtained funding, performed data analysis and wrote the report. All authors participated in study design, interpreted the results, revised the report and approved the final version.

Funding IG was supported by The Danish Agency for Science Technology and Innovation [09-066331]. AH was supported by The Danish Heart Foundation [07-10-R61-A1656-B728-22426F].

Competing interests None.

Ethics approval The Danish Data Protection Agency approved the study and data were made available to us such that individuals could not be identified. According to Danish law, register studies do not require approval by the regional committee on scientific ethics.

Provenance and peer review Not commissioned; externally peer reviewed.

Open Access This is an Open Access article distributed in accordance with the Creative Commons Attribution Non Commercial (CC BY-NC 4.0) license, which permits others to distribute, remix, adapt, build upon this work noncommercially, and license their derivative works on different terms, provided the original work is properly cited and the use is non-commercial. See: http:// creativecommons.org/licenses/by-nc/4.0/

\section{REFERENCES}

1. Malmberg K, Yusuf S, Gerstein HC, et al. Impact of diabetes on long-term prognosis in patients with unstable angina and non-q-wave myocardial infarction: results of the OASIS (Organization to Assess Strategies for Ischemic Syndromes) registry. Circulation 2000;102:1014-19.

2. Gustafsson I, Hildebrandt P, Seibaek M, et al. Long-term prognosis of diabetic patients with myocardial infarction-relation to antidiabetic treatment regimen. Eur Heart J 2000;21:1937-43.

3. Norhammar A, Malmberg K, Ryden L, et al. Under utilisation of evidence-based treatment partially explains for the unfavourable prognosis in diabetic patients with acute myocardial infarction. Eur Heart J 2003;24:838-44.

4. Hasin T, Hochadel M, Gitt AK, et al. Comparison of treatment and outcome of acute coronary syndrome in patients with versus patients without diabetes mellitus. Am J Cardiol 2009;103:772-8.

5. Hasdai D, Granger CB, Srivatsa SS, et al. Diabetes mellitus and outcome after primary coronary angioplasty for acute myocardial infarction: lessons from the gusto-llb angioplasty substudy. Global use of strategies to open occluded arteries in acute coronary syndromes. J Am Coll Cardiol 2000;35:1502-12.

6. Andersen HR, Nielsen TT, Rasmussen K, et al. A comparison of coronary angioplasty with fibrinolytic therapy in acute myocardial infarction. N Engl J Med 2003;349:733-42.

7. Timmer JR, Ottervanger JP, de Boer MJ, et al. Primary percutaneous coronary intervention compared with fibrinolysis for myocardial infarction in diabetes mellitus: results from the primary coronary angioplasty vs thrombolysis-2 trial. Arch Intern Med 2007;167:1353-9.

8. Norhammar A, Malmberg K, Diderholm E, et al. Diabetes mellitus: the major risk factor in unstable coronary artery disease even after consideration of the extent of coronary artery disease and benefits of revascularization. J Am Coll Cardiol 2004;43:585-91.
9. Cannon CP, Weintraub WS, Demopoulos LA, et al. Comparison of early invasive and conservative strategies in patients with unstable coronary syndromes treated with the glycoprotein Ilb/llla inhibitor tirofiban. N Engl J Med 2001;344:1879-87.

10. Wijns W, Kolh P, Danchin N, et al. Guidelines on myocardial revascularization: the task force on myocardial revascularization of the European Society of Cardiology (ESC) and the European Association for Cardio-Thoracic Surgery (EACTS). Eur Heart $J$ 2010;31:2501-55.

11. Bertrand ME, Simoons ML, Fox KA, et al. Management of acute coronary syndromes in patients presenting without persistent ST-segment elevation. Eur Heart J 2002;23:1809-40.

12. Ryden L, Standl E, Bartnik M, et al. Guidelines on diabetes, pre-diabetes, and cardiovascular diseases: executive summary. The task force on diabetes and cardiovascular diseases of the European Society of Cardiology (ESC) and of the European Association for the Study of Diabetes (EASD). Eur Heart $J$ 2007;28:88-136.

13. Anderson JL, Adams CD, Antman EM, et al. ACC/AHA 2007 guidelines for the management of patients with unstable angina/non ST-elevation myocardial infarction: a report of the American College of Cardiology/American Heart Association task force on practice guidelines (writing committee to revise the 2002 guidelines for the management of patients with unstable angina/non ST-elevation myocardial infarction): developed in collaboration with the American College of Emergency Physicians, the Society for Cardiovascular Angiography and Interventions, and the Society of Thoracic Surgeons: endorsed by the American Association of Cardiovascular and Pulmonary Rehabilitation and the Society for Academic Emergency Medicine. Circulation 2007;116:e148-304.

14. [No authors listed]. Invasive compared with non-invasive treatment in unstable coronary-artery disease: FRISC II prospective randomised multicentre study. FRagmin and Fast Revascularisation during InStability in Coronary artery disease investigators. Lancet 1999;354:708-15

15. Vikman S, Airaksinen KE, Tierala I, et al. Improved adherence to practice guidelines yields better outcome in high-risk patients with acute coronary syndrome without ST elevation: findings from nationwide FINACS studies. J Intern Med 2004;256:316-23.

16. Chew DP, Anderson FA, Avezum A, et al. Six-month survival benefits associated with clinical guideline recommendations in acute coronary syndromes. Heart 2010;96:1201-6.

17. Vikman S, Niemela K, Ilva T, et al. Underuse of evidence-based treatment modalities in diabetic patients with non-ST elevation acute coronary syndrome. A prospective nation wide study on acute coronary syndrome (FINACS). Diabetes Res Clin Pract 2003;61:39-48

18. Yan RT, Yan AT, Tan M, et al. Underuse of evidence-based treatment partly explains the worse clinical outcome in diabetic patients with acute coronary syndromes. Am Heart $J$ 2006;152:676-83

19. Brogan GX Jr, Peterson ED, Mulgund J, et al. Treatment disparities in the care of patients with and without diabetes presenting with non-ST-segment elevation acute coronary syndromes. Diabetes Care 2006;29:9-14

20. Dotevall A, Hasdai D, Wallentin L, et al. Diabetes mellitus: clinical presentation and outcome in men and women with acute coronary syndromes. Data from the Euro Heart Survey ACS. Diabet Med 2005;22:1542-50.

21. Bakhai $A$, Collinson J, Flather MD, et al. Diabetic patients with acute coronary syndromes in the UK: high risk and under treated. Results from the prospective registry of acute ischaemic syndromes in the UK (PRAIS-UK). Int J Cardiol 2005;100:79-84.

22. Franklin K, Goldberg RJ, Spencer F, et al. Implications of diabetes in patients with acute coronary syndromes. The global registry of acute coronary events. Arch Intern Med 2004;164:1457-63.

23. Hvelplund A, Galatius S, Madsen M, et al. Women with acute coronary syndrome are less invasively examined and subsequently less treated than men. Eur Heart J 2010;31:684-90.

24. Madsen M, Davidsen M, Rasmussen S, et al. The validity of the diagnosis of acute myocardial infarction in routine statistics: a comparison of mortality and hospital discharge data with the Danish MONICA registry. J Clin Epidemiol 2003;56:124-30.

25. Tu JV, Austin PC, Walld R, et al. Development and validation of the Ontario acute myocardial infarction mortality prediction rules. J Am Coll Cardiol 2001;37:992-7.

26. So L, Evans D, Quan H. ICD-10 coding algorithms for defining comorbidities of acute myocardial infarction. BMC Health Serv Res 2006;6:161.

27. Andersen PK, Abildstrom SZ, Rosthoj S. Competing risks as a multi-state model. Stat Methods Med Res 2002;11:203-15. 
28. Rosthoj S, Andersen PK, Abildstrom SZ. Sas macros for estimation of the cumulative incidence functions based on a cox regression model for competing risks survival data. Comput Methods Programs Biomed 2004;74:69-75.

29. Steyerberg EW, Vickers AJ, Cook NR, et al. Assessing the permance of prediction models: a framework for some traditional and novel measures. Epidemiology 2010;21:128-38.

30. Rasmussen JN, Rasmussen S, Gislason GH, et al. Persistent socio-economic differences in revascularization after acute myocardial infarction despite a universal health care system-a Danish study. Cardiovasc Drugs Ther 2007;21:449-57.

31. Lee $\mathrm{CH}$, Tan M, Yan AT, et al. Use of cardiac catheterization for non-ST-segment elevation acute coronary syndromes according to initial risk: reasons why physicians choose not to refer their patients. Arch Intern Med 2008;168:291-6.

32. Cabana MD, Rand CS, Powe NR, et al. Why don't physicians follow clinical practice guidelines? A framework for improvement. JAMA 1999;282:1458-65.

33. Yan AT, Yan RT, Tan M, et al. Risk scores for risk stratification in acute coronary syndromes: useful but simpler is not necessarily better. Eur Heart J 2007;28:1072-8.

34. Cohen MG, Filby SJ, Roe MT, et al. The paradoxical use of cardiac catheterization in patients with non-ST-elevation acute coronary syndromes: lessons from the can rapid stratification of unstable angina patients suppress adverse outcomes with early implementation of the ACC/AHA guidelines (CRUSADE) quality improvement initiative. Am Heart J 2009;158:263-70.

35. Yan AT, Yan RT, Tan M, et al. Management patterns in relation to risk stratification among patients with non-ST elevation acute coronary syndromes. Arch Intern Med 2007;167:1009-16.

36. Yan AT, Yan RT, Huynh T, et al. Understanding physicians' risk stratification of acute coronary syndromes: insights from the Canadian ACS 2 registry. Arch Intern Med 2009;169:372-8.

37. Elbarouni B, Ismaeil N, Yan RT, et al. Temporal changes in the management and outcome of Canadian diabetic patients hospitalized for non-ST-elevation acute coronary syndromes. Am Heart J 2011;162:347-55.

38. Grol R, Grimshaw J. From best evidence to best practice: effective implementation of change in patients' care. Lancet 2003;362:1225-30.

39. O'Donoghue ML, Vaidya A, Afsal R, et al. An invasive or conservative strategy in patients with diabetes mellitus and non-ST-segment elevation acute coronary syndromes: a collaborative meta-analysis of randomized trials. J Am Coll Cardiol 2012;60:106-11.

40. Goraya TY, Leibson CL, Palumbo PJ, et al. Coronary atherosclerosis in diabetes mellitus: a population-based autopsy study. J Am Coll Cardiol 2002;40:946-53. 